\title{
Student's Self-concept Profile Based on Gender: a Rasch Analysis
}

\author{
Sisca Folastria ${ }^{\mathrm{a}}$, Itsar Bolo Rangka ${ }^{\mathrm{b}}$, Ifdil ${ }^{\mathrm{c}}$ \\ aDept. of Guidance and Counseling, Universitas Indraprasta PGRI, Jakarta, Indonesia \\ bDep. of Guidance and Counseling, Universitas Indraprasta PGRI, Jakarta, Indonesia \\ ${ }^{c}$ Dep. of Guidance and Counseling, Universitas Negeri Padang, Padang, Indonesia
}

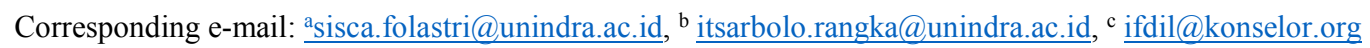

\begin{abstract}
This research aimed to (1) perform inventory self-concept of students, and (2) measuring students' self-concept based on gender. Data analysis used Rasch model for 45 students with actual power measurement 0,84 . The research findings showed (1) inventory self-concept had been fit with the theoretic model, and (2) male students had a tendency to a higher self-concept rather than female students. The implications of this study were the need to increase students' self-concept and improve productivity of students. In addition, the results of this research could be the preliminary data to determine the types of services to solve problems of self-concept of students and positive direction by making counselling program based on students' need assessment.
\end{abstract}

Keywords; $\quad$ student self-concept; gender; rasch model

\section{INTRODUCTION}

Adolescence is a time when many physical and psychological changes. At this time, the developmental shift occurs from the period of the child to early adulthood. These changes continually affect self-concept. In adolescent period, psychological and physiological situations affect large individual development in shaping his personality compared with previous periods. Teenagers begin to seek their true identity based on the learning experience they get.

Self-concept can be interpreted as an individual's perspective in seeing, knowing, feeling, and understanding himself and its relation to the environment [1]-[4]. Moreover, the concept of self can also be viewed as the whole opinion held by everyone as a reality of his personal existence [5]. The self-concept also contains the individual's perspective in assessing and feeling his episodic and semantic memories in himself [6], [7].

Furthermore, self-concept is considered as an important factor and has a close relationship with various human behaviors such as anxiety, academic achievement [8], happiness, and sense of self-worth [2]. Self-concept is influenced by significant person [9]; such as the close relationship with the teacher [10], and is shaped through individual experience with other environments [11]. Many psychologists see self-concept as the foundation of child development [12]-[14]. Several studies have shown that changes occur in student self-concept over the school years [15]. Initially, students in primary schools tend to have a positive self-concept, but when they enter higher education, the self-concept domain of students tends to decline even negative [16], [17].
Though, the self-concept between men and women has many differences [18] [19]. In the academic field, it is known that academic self-concept is part of self-concept [20], where there are differences in academic self-concept between male and female students [21], [22]. Self-concept also provides a difference in perceived emotion [23], [24], in which mood is happy or sadly very influential [25] towards the direction of both male and female activities [26]. In adolescence or at school in secondary education, emotional factors are very influential in the period of development of selfconcept [27], [28]. Students who have a good degree of emotional stability have a direct relationship with academic achievement, teaching, and learning achievement in school [29].

Both male and female students are very concerned about their physical appearance [28], but male students have higher self-concept than female students in the physical appearance domain [30]. Good physical appearance gives students confidence in themselves [31]. In addition, the physical condition of excellent students has a positive relationship with students' academic achievement in school [32].

Self-concept also affects individuals in shaping social behavior in society [33]. Concerning selfconcept in the effort to foster social relationships with others, female students believe a social relationship and have better social relationships are more important than male students [34]. Social acceptance built through a good social relationship by students also has a good impact on students' efforts to attain academic achievement in school [35]. As a multidimensional construct [36], self-concept measurement in this study is divided into several units of measurement, i.e. physical condition, social 
relationships, and emotional state of students in school. For that reason, the measurements are used Rasch modeling to estimate students' self-concepts.

Rasch modeling is the development of Item Response Theory (IRT) which has grown rapidly since the 1960s, particularly in the field of Social and Behavioral Sciences [37]. The Rasch Model is considered an analytical method that has many advantages for providing objective measures, including: (1) providing a linear measure, (2) overcoming missing data, (3) having precise estimates, (3) finding misfits and outliers in the data, and (5) provides a measurement instrument independent of the parameters studied [37], [38]. The advantages mentioned are not obtained from the Classical Test Theory (CTT), which has been widely used by scientists Social and Behavioral Sciences, where the CTT is still influenced by the type of subject, assessment characteristics, sample size, the effect of limit and ceiling (floor-ceiling effect), as well as the characteristics of measuring instruments. Selfconcept measurement with Rasch modeling is considered as appropriate instrument because the concept of self-concept is a latent attribute, or in other words is hypothetic and can't be observed directly. Another background that encouraged the use of Rasch modeling was the fact that criticism of the interpretation of self-concept measurement was considered invalid [39].

The purpose of this research are; (1) to test the theoretical model related self-concept of vocational students covering three aspects, namely physical condition, social relationship, emotional state, and; (2) measuring self-concept of vocational students both male and female students. By knowing the selfconcept of male and female students, BK teachers can develop self-concept of the students in a positive direction such as self-confidence, courage, passion in doing activities including in learning, have selfconfidence, courageous, often present, active learning, and become an independent person. Moreover, BK teachers can also design a $\mathrm{BK}$ program about selfconcept so that students have a positive understanding of themselves.

\section{METHOD}

The research method used in this research was survey method. This research was conducted at SMK Sumbangsih South Jakarta with total of population were 45 students, aged 16-18 years. From the total population, the sample size of the study was eligible for the calibration of item \pm 1 logit and $99 \%$ confidence level, in the sample range 27-61 [38], [40]. Therefore, the sample is determined for 45 students, consisted of 28 male students and 17 female students.

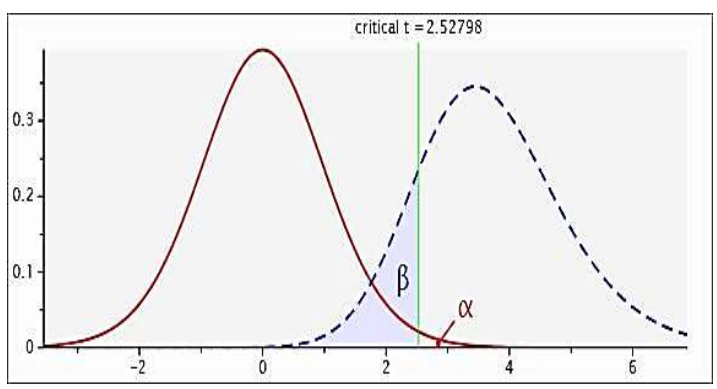

Figure 1. Measurement of power Estimasi pengukuran based on total samples to get stablity of statistic value.

With a predetermined sample size, the estimated power generated to measure the stability of the statistical value in this study sample that is equal to $0.84(\mathrm{~N} 1 \neq \mathrm{N} 2,1-\beta$ err prob $=0.80$ and $\alpha$ err prob $=$ $0.1)$ which means strong. Referring to the critical $t$ value generated, that is 2.52 on the total sample size $\mathrm{N}=22$, the sample size of the data in this study ( $\mathrm{N}=$ 45 ) is indicated met the criteria of sample size used for measurement. Likewise, the sample representation of the study has also met the criteria as it is taken randomly in each class.

To collect data, this research used self-concept questionnaire with three aspects of measurement (physical condition, social relations, and emotional condition). The questionnaire contains 15 points by using likert rating with five answer choices. To achieve the goal in this study used data analysis with RASCH modeling [37], [41] with Winstep 4.0 program.

\section{RESULT AND DISCUSSIONS}

Self-concept of vocational students in this study include (1) testing theoretical models of data collection instruments, and (2) analyzing self-concept of SMK students in terms of Gender based on theoretical model that has been compiled.

\subsection{Terroristic Construct Testing of Research Instrument}

The Global Test of Fit test which aims to provide information regarding the quality of respondents, the quality of research instruments used, and the interaction between the respondents with the items both separately and overall used to measure selfconcept of students in SMK, found that the modeling used in accordance with the construct of theoretical research.

Table 1. Global Test of Fit of Students' Inventory ( $\mathrm{I}=15, \mathrm{~N}=45$ )

Person Summary Measured

Item-Person Reliability 0.74-Cronbach Alpha (KR-20) Person Raw Score "Test" Reliability

Standard Error Item Mean 0.35 
The average score of students $(\mathrm{N}=45)$ in the selfconcept instrument of SMK students is at +1.72 logit. This shows the students are tend to approve more the statement on various self-concept items $(+1.72$ logit $\geq$ 0.00 logit). Judging from the reliability aspects of the overall measurement (item and person), known reliability score reached 0.74 . This means that the interaction between the items in the instrument with the respondents when the research done can be interpreted as good.

Table 2. Estimation of Logit Items Value and Person Inventory of Students' Self-concept $(\mathrm{I}=15, \mathrm{~N}=45)$

\begin{tabular}{cccc}
\hline Items & \multicolumn{3}{c}{ Person } \\
\hline Mean & 0.00 & Mean & 1.72 \\
SD & 1.32 & SD & 0.79 \\
Reliability & 0.96 & Reliability & 0.72 \\
INFIT MNSQ & 0.99 & INFIT MNSQ & 1.00 \\
OUTFIT MNSQ & 1.00 & OUTFIT MNSQ & 1.00 \\
INFIT ZSTD & -0.1 & INFIT ZSTD & -0.1 \\
OUTFIT ZSTD & -0.1 & OUTFIT ZSTD & -0.1 \\
Separation Index & 4.89 & Separation Index & 1.60 \\
\hline
\end{tabular}

By seeing the value of person reliability and item reliability separately, it can be concluded that the quality of items in the instrument are very good (0.96), nonetheless, they were not balanced with the consistency of answers from all the respondents whose results are good $(0.72)$.

The average respondents' sensitivity (INFIT MNSQ) was at +1.00 logit, and the sensitivity of the respondents' difficulty level (OUTFIT MNSQ) was at +1.00 logit. The values are still within the ideal number of measurement distortions $(+0.5$ logit to +1.5 logit), or in other words, all persons (respondents) when measured are in the best condition to answer the instrument items provided by Researchers. Then the average sensitivity of the answer pattern (INFIT ZSTD) is at -0.1 logit, and the difficulty level sensitivity (OUTFIT ZSTD) is at -0.1 logit. These values are in the size of the data having logical estimates ( -1.9 logit to +1.9 logit), or data provided by all respondents according to the proposed theoretical model.

Average instrument item sensitivity (INFIT MNSQ) was at +0.99 logit, and the sensitivity of item difficulty level (OUTFIT MNSQ) at +1.00 logit. These values are still within the ideal number of measurement distortions $(+0.5$ logit to +1.5 logit $)$, or all items are of good quality for measurement. Furthermore, the mean sensitivity of the answer pattern (INFIT ZSTD), and the difficulty level sensitivity (OUTFIT ZSTD) of all items in sequence are -0.1 logit and -0.1 logit. These values are in the size of the data having logical estimates (-1.9 logit to +1.9 logit), or data generated by each instrument item in accordance with the proposed theoretical model.

In addition, the separation index value of item and person in sequence are +4.89 logit and +1.60 logit. This reflects the grouping of persons and items in this study, either because it can identify or classify existing data (separation $\geq 0.00$ logit). Evaluation of instrument measurement capability to measure what should be measured, in this case is the construct of self-concept. The analysis was used Principal Component Analysis (PCA). Description of unidimensional tests as shown in Table 2 below.

Table 3. Principal Component Analysis (PCA)

\begin{tabular}{ccc}
\hline Principal Component Analysis & Observed & Expected \\
\hline Total raw variance in observations & $100.0 \%$ & $100.0 \%$ \\
Raw variance explained by & $48.2 \%$ & $47.6 \%$ \\
measures & $14.3 \%$ & $14.1 \%$ \\
Raw variance explained by persons & $33.9 \%$ & $33.5 \%$ \\
Raw Variance explained by items & $51.8 \%$ & $52.4 \%$ \\
Raw unexplained variance (total) & & \\
Unexplained variance in 1st & & \\
contrast & $9.3 \%$ & $17.9 \%$ \\
Unexplained variance in 2nd \\
contrast \\
Unexplained variance in 3rd \\
contrast \\
contrast \\
Unexplained variance in 4th
\end{tabular}

The percentage of the result of total raws variance in observations measurement above is $48.2 \%$. It indicates that the unidimensionality test requirements are met $(\geq 20 \%)$. Another point, namely variance that can't be explained by the research instrument in sequence that are $9.3 \%, 8.1 \%, 6.6 \%, 5.1 \%$, and $4.0 \%$. It can be said appropriate for measurements because the percentage of variance unexplained in the study does not exceed $15 \%$.

Tabel 4. Rating Scale Test

\begin{tabular}{crc}
\hline & $\begin{array}{c}\text { Observed } \\
\text { Average }\end{array}$ & $\begin{array}{c}\text { Andrich } \\
\text { Threshold }\end{array}$ \\
\hline Strongly Disagree (1) & -0.72 & None \\
Disagree (2) & 0.06 & -2.45 \\
Not Sure (3) & 0.78 & -0.48 \\
Agree (4) & 1.53 & 0.46 \\
Strongly Disagree (5) & 3.12 & 2.47 \\
\hline
\end{tabular}

Based on Table 3, the average value of observation starts from -0.72 logit for the choice of answers that got score of 1 ; +0.06 logit for answer choice that got score 2; choice of answers that got score of 3 is +0.78 logit; +1.53 logit for answer choices that got a score of 4 , and; +3.12 logit for the choice of answers that got a score of 5. Logit score on each choice of answer shows the difference of small logit value for answer choice with minimum score, to logit value for big answer choice with maximum score. This means that respondents can ascertain the difference between the answer choices provided in the self-concept instrument.

Moreover, the average value of observations was relevant to Andrich Threshold value which moved from NONE then moves toward a negative logit and continues lead to a positive logit for each choice of answer indicating that the given answer option is 
valid (NONE -> -2.45 Logit $->-0.48$ logit $->+0.48$ logit $->+2.47$ logit). In this case, the suitability between the items with the answer choice is ideal.

Measurements of the DIF person for all selfconcept instrument items of students are known above probability $(\geq 0.05)$. This shows all items have no gender bias. Male and female students do not feel disadvantaged or benefited by the items proposed in the study.

\subsection{The students' Self-concept Based on Gender}

Based on the analysis of self-concept instrument items, students found that item number 14, "I am stubborn", has the greatest logit value $(+1.99$ logit). This reflects that item 14 is the most difficult item to be approved by the respondents. Generally, students refuse to describe themselves as stubborn people.

The self-concept sequence is based on the item logit score from the most difficult to the most easily approved / performed by the students as presented in Table 5 below.

Table 5. Self-concept of Students based on logit item $(\mathrm{I}=15, \mathrm{~N}=45)$

\begin{tabular}{ccc}
\hline No. Item & Questions & $\begin{array}{c}\text { Logit } \\
\text { Value }\end{array}$ \\
\hline 14 & I am stubborn & +1.99 \\
5 & I look attractive & +1.17 \\
15 & I am easily discouraged & +1.14 \\
12 & My emotions are not stable & +1.00 \\
10 & I'm hard to get along with others & +0.59 \\
7 & Friends are important things in my & +0.55 \\
1 & life & +0.47 \\
4 & My physical endurance is weak & +0.47 \\
11 & (easy to get tired and sick) & +0.01 \\
6 & I have a strong urge to learn & -0.04 \\
9 & I love to help & -0.13 \\
2 & I refuse to cooperate with people if I & -0.81 \\
3 & I am able to understand others well & -0.93 \\
13 & I have an ideal posture & -2.15 \\
8 & I am a wise person & -3.34 \\
\hline
\end{tabular}

Meanwhile item no. 8 , has the smallest logit value (-3.34 logit) for all items given in the student selfconcept instrument. This indicates that the item "I am a person who can be useful for others", is the most agreeable conditions by the respondents. The respondents were inclined to give consent that they were individuals who could benefit to others.

When compared with the lowest item value, item no. 8 (-3.34 logit), it can be stated that item no. 14 has a fourfold higher value than item no. 5. Furthermore, other than item no. $14(+1.99$ logit $)$, then the item logit value as shown in Table 5 above is still below the average logit value of all respondents $(+1.72$ logit). This means that conditions decomposed in statements submitted to self-concept instruments generally tend to be approved by all students.

Table 6. Measure order Male and Female Students $(\mathrm{I}=15, \mathrm{~N}=45)$

\begin{tabular}{|c|c|c|c|}
\hline \multicolumn{2}{|c|}{ Male } & \multicolumn{2}{|c|}{ Female } \\
\hline Person & Measure & Person & Measure \\
\hline $29 \mathrm{~L}$ & +4.01 & & \\
\hline $30 \mathrm{~L}$ & +3.20 & & \\
\hline $26 \mathrm{~L}$ & +2.99 & & \\
\hline $31 \mathrm{~L}$ & +2.99 & & \\
\hline $34 \mathrm{~L}$ & +2.44 & & \\
\hline $36 \mathrm{~L}$ & +2.27 & 15P & \\
\hline $23 \mathrm{~L}$ & +2.12 & 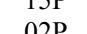 & +3.20 \\
\hline $24 \mathrm{~L}$ & +2.12 & $\begin{array}{l}02 \mathrm{P} \\
08 \mathrm{P}\end{array}$ & +2.79 \\
\hline $21 \mathrm{~L}$ & +1.97 & $08 \mathrm{P}$ & +2.61 \\
\hline $22 \mathrm{~L}$ & +1.97 & $16 \mathrm{P}$ & +2.12 \\
\hline $19 \mathrm{~L}$ & +1.83 & $17 \mathrm{P}$ & +2.12 \\
\hline $20 \mathrm{~L}$ & +1.56 & $12 \mathrm{P}$ & +1.97 \\
\hline $37 \mathrm{~L}$ & +1.56 & $01 \mathrm{P}$ & +1.83 \\
\hline 39L & +1.56 & $05 \mathrm{P}$ & +1.83 \\
\hline $40 \mathrm{~L}$ & +1.56 & $06 \mathrm{P}$ & +1.83 \\
\hline $25 \mathrm{~L}$ & $\begin{array}{l}+1.50 \\
+1.43\end{array}$ & 07P & +1.83 \\
\hline $28 \mathrm{~L}$ & $\begin{array}{l}+1.43 \\
+1.43\end{array}$ & $13 \mathrm{P}$ & +1.83 \\
\hline $18 \mathrm{~L}$ & $\begin{array}{r}+1.43 \\
+1.31\end{array}$ & $10 \mathrm{P}$ & +1.56 \\
\hline $43 \mathrm{~L}$ & $\begin{array}{l}+1.31 \\
+1.31\end{array}$ & $11 \mathrm{P}$ & +1.31 \\
\hline $27 \mathrm{~L}$ & $\begin{array}{l}+1.51 \\
+1.19\end{array}$ & 09P & +1.19 \\
\hline $45 \mathrm{~L}$ & $\begin{array}{l}+1.19 \\
+1.19\end{array}$ & $14 \mathrm{P}$ & +0.95 \\
\hline $32 \mathrm{~L}$ & $\begin{array}{r}1.13 \\
+1.07\end{array}$ & 03P & +0.73 \\
\hline $41 \mathrm{~L}$ & $\begin{array}{r}1.07 \\
+1.07\end{array}$ & 04P & +0.39 \\
\hline $42 \mathrm{~L}$ & +0.95 & & \\
\hline $44 \mathrm{~L}$ & +0.84 & & \\
\hline $35 \mathrm{~L}$ & +0.73 & & \\
\hline $38 \mathrm{~L}$ & +0.61 & & \\
\hline $33 \mathrm{~L}$ & +0.17 & & \\
\hline
\end{tabular}

Although item no. 14 is the most difficult item to be approved by all students, but there are 22 students showing different approvals (Outlier). Outlier students are students who have a logit person who exceeds the average value of the highest item logit in the students' self-concept instrument $(\geq+1.72$ logit). Outlier students consist of 11 males and 11 females. This shows that there are 22 students who have a tendency to describe themselves as stubborn.

Based on Table 6 also obtained information that 29L male student have the highest logit of person (+4.01 logit), meanwhile female 04P student is the student with the lowest logit score of person $(+0.39$ logit).

\section{CONCLUSIONS}

Based on the description that has been proposed, it can be concluded that (1) the student self-concept instrument has been in accordance with the proposed theoretical model, and (2) male students have a tendency to have higher self-concept rather than female students.

Overall, students tend to refuse to portray themselves as stubborn people, and tend to describe themselves as individuals capable of benefiting others.

For future research involving selfconceptualization in terms of gender, it is necessary to 
broaden the investigation of more specific selfconcept issues in various contexts.

\section{ACKNOWLEDGMENT}

We would like to thank Universitas Negeri Padang and Universitas Indraprasta PGRI for the financial assistant under the Fundamental Research Grant. We express our great appreciation to all of the children in SMK Sumbangsih Jakarta who participated and their friendly cooperation, and Ms. Nosmalasari for technical help in this manuscript.

\section{REFERENCES}

[1] A. Sullivan, "Academic self-concept, gender and single sex schooling," Br. Educ. Res. J., vol. 35, no. 2, pp. 259-288, 2009.

[2] H. W. Marsh and A. J. Martin, "Academic self-concept and academic achievement: relations and causal ordering.," Br. J. Educ. Psychol., vol. 81, no. Pt 1, pp. 59-77, 2011.

[3] K. Gana, Psychology of Self-Concept. New York: Nova Science Publishers, Inc., 2012.

[4] A. M. Kaba and Y. Talek, "Self-Concept and Academic Success Among University Students," Int. J. Arts Sci., vol. 8, no. 1, pp. 89-102, 2015.

[5] M. Meshkat and S. M. Hosseini, "The Relationship Between Academic SelfConcept and Learning English in High School Student," Mod. J. Lang. Teach. Methods, vol. 4, no. 5, pp. 383-389, 2015.

[6] Y. Ommundsen, R. Haugen, and T. Lund, "Academic Self-concept, Implicit Theories of Ability, and Self-regulation Strategies," Scand. J. Educ. Res., vol. 49, no. 5, pp. 461474, 2005.

[7] E. Goñi Palacios, I. Esnaola Echaniz, A. Rodríguez Fernández, and I. Camino Ortiz de Barrón, "Personal self-concept and satisfaction with life in adolescence, youth and adulthood.," Psicothema, vol. 27, no. 1, pp. 52-58, 2015.

[8] M. A. Albert and J. J. Dahling, "Learning goal orientation and locus of control interact to predict academic self-concept and academic performance in college students," Personality and Individual Differences, vol. 97. pp. 245-248, 2016.

[9] M. Bong and E. M. Skaalvik, "Academic self-concept and self-efficacy: How different are they really?," Educ. Psychol. Rev., vol. 15, no. 1, pp. 1-40, 2003.

[10] L. McFarland, E. Murray, and S. Phillipson, "Student-teacher relationships and student self-concept: Relations with teacher and student gender," Aust. J. Educ., vol. 60, no. 1, pp. 5-25, 2016.

[11] H. Ling, Y. Luo, and J. Zhang, "Relationship
Between Self-Supporting Behaviors and SelfConcept Among Primary School Students in China," Soc. Behav. Pers., vol. 41, no. 8, pp. 1245-1252, 2013.

[12] S. D. Pyankova, O. V. Baskaeva, Y. D. Chertkova, and O. V. Parshikova,

"Relationships between Intelligence and Selfconcept Parameters in Children," Procedia Soc. Behav. Sci., vol. 233, no. May, pp. 362366, 2016.

[13] H. W. Marsh, L. A. Ellis, and R. G. Craven, "How do preschool children feel about themselves? Unraveling measurement and multidimensional self-concept structure.," Dev. Psychol., vol. 38, no. 3, pp. 376-393, 2002.

[14] S. L. Kagan et al., Reconsidering Children's Early Development and Learning: Toward Common Views and Vocabulary. 1995.

[15] M. Sáinz and K. Upadyaya, "Accuracy and bias in Spanish secondary school students' self-concept of math ability: The influence of gender and parental educational level," Int. J. Educ. Res., vol. 77, pp. 26-36, 2016.

[16] J. E. Jacobs, S. Lanza, D. W. Osgood, J. S. Eccles, and A. Wigfield, "Changes in Children's Self-Competence and Values: Gender and Domain Differences across Grades One through Twelve," Child Dev., vol. 73, no. 2, pp. 509-527, 2002.

[17] T. Bouffard, C. Vezeau, M. Roy, and A. Lengelé, "Stability of biases in selfevaluation and relations to well-being among elementary school children," Int. J. Educ. Res., vol. 50, no. 4, pp. 221-229, 2011.

[18] S. A. Lee, E. J. Choi, S. Kwon, and S. Eom, "Self-concept and gender effects in Korean adolescents with epilepsy," Epilepsy Behav., vol. 61, pp. 102-106, 2016.

[19] L. A. Jackson, A. von Eye, H. E. Fitzgerald, Y. Zhao, and E. A. Witt, "Self-concept, selfesteem, gender, race and information technology use," Comput. Human Behav., vol. 26, no. 3, pp. 323-328, 2010.

[20] R. Shahid, "Academic Self Concept and Academic Achievement Among Undergraduates in Universities of Pakistan : a Gender Perspective," vol. 45, no. 1, pp. 197232, 2016.

[21] M. Baran and A. K. Maskan, "A study of relationships between academic self concepts , some selected variables and physics course achievement," Int. J. Educ., vol. 3, no. 1, pp. 1-12, 2011.

[22] M. Kavutha and M. Kariuki, "Influence of Drug Use on Academic Performance among Secondary School Students in Matinyani District, Kenya," Jackline Kavutha, vol. 5, no. 11, pp. 726-731, 2015.

[23] J. D. Brown and M. A. Marshall, "Self- 
Esteem and Emotion: Some Thoughts about Feelings," Personal. Soc. Psychol. Bull., vol. 27, no. 5, pp. 575-584, May 2001.

[24] P. E. Flores Kanter, L. Medrano, and H. Conn, "Does Mood Affect Self-Concept? Analysis through a Natural Semantic Networks Based Approach," Int. J. Behav. Res. Psychol., vol. 3, no. 5, pp. 114-120, 2015.

[25] R. A. Good et al., "Nutritional deficiency, immunologic function, and disease.," Am. J. Pathol., vol. 84, no. 3, pp. 599-614, Sep. 1976.

[26] U. Athenstaedt, G. Mikula, and C. Bredt, "Gender Role Self-Concept and Leisure Activities of Adolescents," Sex Roles, vol. 60, no. 5-6, pp. 399-409, Mar. 2009.

[27] S. Hangal and V. A. Aminbhavi, "Selfconcept, emotional maturity and achievement motivation of the adolescent children of employed mothers and homemakers," $J$. Indian Acad. Appl. Psychol., vol. 33, no. 1, pp. 103-110, 2007.

[28] R. M. Lerner, S. A. Karabenick, and J. L. Stuart, "Relations among Physical Attractiveness, Body Attitudes, and SelfConcept in Male and Female College Students," J. Psychol., vol. 85, no. 1, pp. 119-129, Sep. 1973.

[29] T. Goetz et al., "Students' emotions during homework: Structures, self-concept antecedents, and achievement outcomes," Learn. Individ. Differ., vol. 22, no. 2, pp. 225-234, 2012.

[30] A. T. Klomsten, E. M. Skaalvik, and G. A. Espnes, "Physical Self-Concept and Sports: Do Gender Differences Still Exist?," Sex Roles, vol. 50, no. 1/2, pp. 119-127, Jan. 2004.

[31] M. M. Chemers, L. Hu, and B. F. Garcia, "Academic self-efficacy and first year college student performance and adjustment.," J. Educ. Psychol., vol. 93, no. 1, pp. 55-64, 2001.

[32] D. M. Castelli, C. H. Hillman, S. M. Buck, and H. E. Erwin, "Physical Fitness and
Academic Achievement in Third- and FifthGrade Students," J. Sport Exerc. Psychol., vol. 29, no. 2, pp. 239-252, Apr. 2007.

[33] H. C. Triandis, "The self and social behavior in differing cultural contexts.," Psychol. Rev., vol. 96, no. 3, pp. 506-520, 1989.

[34] J. a O'Dea and S. Abraham, “Association between self-concept and body weight, gender, and pubertal development among male and female adolescents.," Adolescence, vol. 34, no. 133, pp. 69-79, 1999.

[35] K. R. Wentzel, "Social relationships and motivation in middle school: The role of parents, teachers, and peers.," J. Educ. Psychol., vol. 90, no. 2, pp. 202-209, 1998.

[36] M. Jansen, U. Schroeders, and O. Lüdtke, "Academic self-concept in science: Multidimensionality, relations to achievement measures, and gender differences," Learn. Individ. Differ., vol. 30, pp. 11-21, 2014.

[37] T. G. Bond and C. M. Fox, Applying the Rasch model : fundamental measurement in the human sciences, Third. New York, USA: Routledge, 2015.

[38] B. Sumintono and Wahyu Widhiarso, Aplikasi Pemodelan Rasch untuk Penelitian Ilmu-ilmu Sosial. Cimahi, Indonesia: Trim Komunikata Publishing House, 2014.

[39] R. J. Shavelson, J. J. Hubner, and G. C. Stanton, "Self-Concept: Validation of Construct Interpretations," Rev. Educ. Res., vol. 46, no. 3, pp. 407-441, 1976.

[40] R. J. Wirth, C. R. Houts, and L. S. Deal, "Rasch Modeling with Small Samples: A Review of the Literature have recently advocated for an early-stage quantitative analysis , using a small additional sample , during the scale items which may not appear problematic from qualitative results 2 )

Avoid," Vector Psychometrics Group. ISPOR, p. 2, 2016.

[41] N. Verhelst, "Testing the unidimensionality assumption of the Rasch model," Methods Psychol. Res. Online, vol. 6, no. 3, pp. 231271, 2001. 